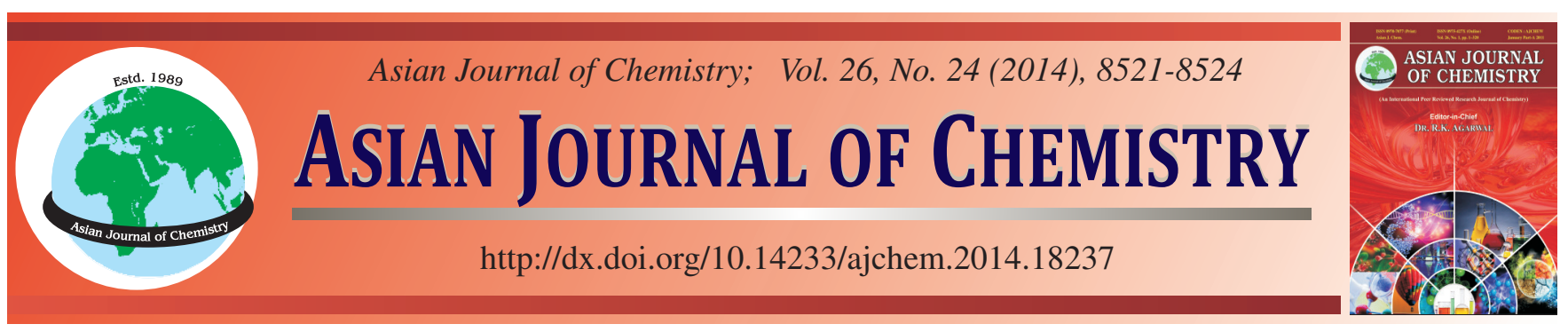

\title{
Synthesis and Structures of Two Mononuclear Cu(II) Complexes Derived from 3-Methoxysalicylaldehyde Benzoylhydrazide Ligand
}

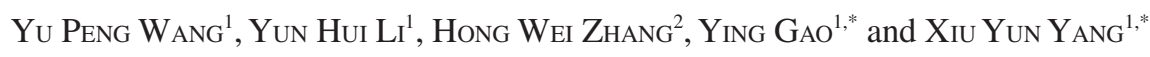

${ }^{1}$ School of Chemistry and Environmental Engineering, Changchun University of Science and Technology, Changchun 130022, P.R. China ${ }^{2}$ Changchun Extrawell Pharmaceutical Co. Ltd., Changchun130000, P.R. China

*Corresponding authors: Fax: +86 431 84727678; Tel: +86 431 85582361; E-mail: liyh@ @ust.edu.cn

\begin{abstract}
Reaction of 3-methoxysalicylaldehyde benzoylhydrazide $\left(\mathrm{H}_{2} \mathrm{~L}\right)$ with $\mathrm{Cu}\left(\mathrm{ClO}_{4}\right)_{2} \cdot 6 \mathrm{H}_{2} \mathrm{O}$ and heterocycle(imidazole or pyrazol) in methanol results in the formation of two isostructural mononuclear $\mathrm{Cu}(\mathrm{II})$ complexes, in which the metal ion is coordinated to the hydrazine- $\mathrm{N}$, carbonyl-O and deprotonated phenolate- $\mathrm{O}$ of $\mathrm{H}_{2} L$ and the imine- $\mathrm{N}$ atom of the neutral heterocycle, forming a distorted square-planar coordination configuration. In the crystal structure of complexes $\mathbf{1}$ and $\mathbf{2}$, the uncoordinated perchlorate anion is involved in forming intramolecular hydrogen bond. Additionally, complex 2 forms a centrosymmetric dimeric species due to weak apical coordination of the phenolate-O in a reciprocal fashion.
\end{abstract}

Keywords: Copper complex, Crystal structure, Mononuclear.

\section{INTRODUCTION}

The design and synthesis of acylhydrazone ligands and their corresponding metal complexes have received considerable attention ${ }^{1}$, as a result of which not only play important roles in the development of coordination chemistry related to magnetism ${ }^{2}$, enzymatic reactions ${ }^{3}$ and pharmacological applications ${ }^{4}$, but also exhibit variety of biological activities ${ }^{5}$.

Schiff base ligands formed by reaction between the $o$ vanillin group and benzoylhydrazine (3-methoxysalicylaldehyde benzoylhydrazide, hereafter abbreviated as $\mathrm{H}_{2} L$ ) is good candidates to construct metal clusters. The $\mathrm{H}_{2} L$ has Oor N-donors and these donors with suitable relative positions in the ligand can coordinate to metal centers ${ }^{6,7}$. Furthermore, the vanillin group displays a variety of bonding geometries, such as chelating, monodentate bridging, bidentate bridging and chelating bridging, although the coordination ability of the vanillin group is not strong in some $\operatorname{cases}^{8,9}$.

$\mathrm{N}$-donor heterocycles can react with coordinatively unsaturated copper(II) complexes to give varieties of complexes where the heterocycles molecule is coordinated to the $\mathrm{Cu}$ (II) via the $\mathrm{N}$-donor ${ }^{10,11}$. Interestingly, the self-assembly patterns of the complexes having the general formula $[\mathrm{Cu}(\mathrm{L})(\mathrm{hc})]$ with other monodentate $\mathrm{N}$-donor heterocycles $(L=$ acylhy-drazone ligand, hc = pyrazole, imidazole or pyridine) are different ${ }^{12,13}$.

Herein, we reported two $\mathrm{Cu}(\mathrm{II})$ complexes, $[\mathrm{Cu}(\mathrm{HL})-$ (imidazole) $] \cdot \mathrm{ClO}_{4}(\mathbf{1})$ and $[\mathrm{Cu}(\mathrm{HL})($ pyrazol $)] \cdot \mathrm{ClO}_{4}(\mathbf{2})$, using substituted a monodentate N-donor heterocycle. Their crystal structures are also studied.

\section{EXPERIMENTAL}

All the reagents and solvents employed were commercially available and used as received without further purification. The 3-methoxysalicylaldehyde benzoylhydrazide ligand $\left(\mathrm{H}_{2} \mathrm{~L}\right)$ was prepared in a similar manner according to the reported procedures ${ }^{14,15}$. Elemental analysis for $\mathrm{C}, \mathrm{N}$ and $\mathrm{H}$ were performed with a Perkin-Elmer 2400 II analyzer.

Caution! Although we did not experience any problem during the work, perchlorate salts in presence of organic materials are potentially explosive. They should be used in small quantities and handled with extreme care.

Preparation of complexes: The complex 1 was synthesized by adding $\mathrm{Cu}\left(\mathrm{ClO}_{4}\right)_{2} \cdot 6 \mathrm{H}_{2} \mathrm{O}(37 \mathrm{mg}, 0.10 \mathrm{mmol})$ to a solution of $\mathrm{H}_{2} L$ (27.3 mg, $\left.0.1 \mathrm{mmol}\right)$ in methanol $(10 \mathrm{~mL})$. After stirring for $3 \mathrm{~h}$, imidazole ( $13.6 \mathrm{mg}, 0.2 \mathrm{mmol}$ ) was added to the resulting solution. Green crystals were isolated from the solution after two weeks. Yield: $37.6 \%$ (based on $\mathrm{Cu}$ ). Elemental analysis (\%) calcd. for $\mathrm{C}_{18} \mathrm{H}_{17} \mathrm{~N}_{4} \mathrm{O}_{7} \mathrm{CuCl}$ : C, 43.21; $\mathrm{H}, 3.42$; N, 11.20; found C, 43.27; H, 3.40; N, 11.18.

Complex 2 was obtained by a similar procedure to that for $\mathbf{1}$, but using pyrazol in place of imidazole. Green crystals formed after two weeks. Yield: $35.9 \%$ (based on $\mathrm{Cu}$ ). Elemental analysis (\%) calcd. for complex $2 \mathrm{C}_{18} \mathrm{H}_{17} \mathrm{~N}_{4} \mathrm{O}_{7} \mathrm{CuCl}$ : C, 43.21; H, 3.42; N, 11.20; found C, 43.25; H, 3.40; N, 11.19 . 
X-Ray crystallography: Crystallographic data were collected on a Bruker Apex II CCD diffractometer with graphite monochromated $\mathrm{MoK}_{\alpha}$ radiation $(\lambda=0.71073 \AA)$ at a temperature of $185( \pm 2) \mathrm{K}$, for complexes 1 and 2 . Data processing was accomplished with the SAINT processing program. These structures were solved by the direct methods and refined on $\mathrm{F}^{2}$ by full-matrix least squares using SHELXTL97 ${ }^{16,17}$. The location of $\mathrm{Cu}$ atom was easily determined and $\mathrm{O}, \mathrm{N}$ and $\mathrm{C}$ atoms were subsequently determined from the difference Fourier maps. All non-hydrogen atoms were refined with anisotropic thermal parameters. Crystallographic data and refinement details of complexes $\mathbf{1}$ and $\mathbf{2}$ are listed in Table-1. CCDC-998370 and CCDC-998371 contain the supplementary crystallographic data for this paper. These data can be obtained free of charge from the Cambridge Crystallographic Data Centre via www.ccdc.cam.ac.uk/data_request/cif. [or from the Cambridge Crystallographic Data Centre (CCDC), 12 Union Road, Cambridge CB2 1EZ, UK; fax: (44) 1223-336033; email: deposit@ccdc.ccam.ac.uk].

\section{RESULTS AND DISCUSSION}

Complexes $\mathbf{1}$ and $\mathbf{2}$ crystallize in triclinic space group $\mathrm{P} \overline{1}$. The structures of the complexes are illustrated in Figs. 1 and 2. The selected bond parameters are listed in Tables 2 and 3 . Both complexes have a distorted square-planar geometry. In each complex, the metal ion is coordinated to the hydrazine$\mathrm{N}$, carbonyl-O and deprotonated phenolate- $\mathrm{O}$ of $\mathrm{H}_{2} \mathrm{~L}$ and the imine- $\mathrm{N}$ atom of the neutral heterocycle. The $\mathrm{C}-\mathrm{O}$ and $\mathrm{C}-\mathrm{N}$ bond lengths in the amide functionality of the tridentate ligand are within 1.255(5)-1.439(6) and 1.288(6)-1.388(6) $\AA$, respectively. These values are in accord with the enolate form of the amide functionality ${ }^{18,19}$. The $\mathrm{Cu}-\mathrm{O}$ (phenolate) (1.892(3)$1.910(3) \AA$ ) and $\mathrm{Cu}-\mathrm{N}$ (hydrazine) (1.917(4)-1.923(3) $\AA$ ) bond lengths are comparable to the bond lengths observed in

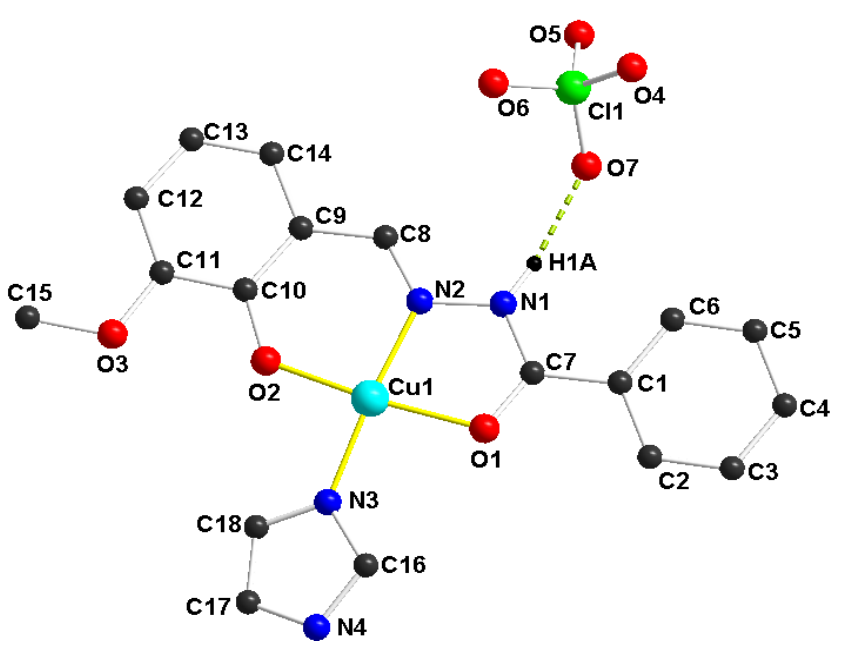

Fig. 1. A view of the complex $\mathbf{1}$, showing the atomic numbering scheme

\begin{tabular}{|c|c|c|c|}
\hline \multicolumn{4}{|c|}{$\begin{array}{c}\text { TABLE-2 } \\
\text { SELECTED BOND LENGTHS }(\AA) \text { AND } \\
\text { ANGLES }\left({ }^{\circ}\right) \text { FOR COMPLEX } 1\end{array}$} \\
\hline \multicolumn{4}{|c|}{ Bond lengths } \\
\hline Cu1-O1 & $1.985(3)$ & Cu1-N2 & $1.917(4)$ \\
\hline $\mathrm{Cu} 1-\mathrm{O} 2$ & $1.892(3)$ & Cu1-N3 & $1.940(4)$ \\
\hline \multicolumn{4}{|c|}{ Bond angles } \\
\hline $\mathrm{O} 2-\mathrm{Cu} 1-\mathrm{O} 1$ & $172.61(14)$ & $\mathrm{O} 2-\mathrm{Cu} 1-\mathrm{N} 2$ & $92.45(15)$ \\
\hline N2-Cu1-O1 & $81.16(15)$ & $\mathrm{O} 2-\mathrm{Cu} 1-\mathrm{N} 3$ & $91.05(15)$ \\
\hline N3-Cu1-O1 & $94.98(15)$ & N2-Cu1-N3 & $173.69(17)$ \\
\hline
\end{tabular}

copper(II) complexes having the same coordinating atoms ${ }^{20-22}$. In addition, the $\mathrm{Cu}-\mathrm{N}$ (heterocycle) bond lengths of both complexes are in the range of 1.939(3)-1.940(4) $\AA$ are unexceptional $^{18,22}$. In each complex, the satisfactory square plane is constructed by a $\mathrm{O}_{2} \mathrm{~N}_{2}$ donor around the $\mathrm{Cu}$ (II) metal ion. The $\mathrm{Cu}$ (II) metal centers lie 0.067 and $0.075 \AA$ above the $\mathrm{O}_{2} \mathrm{~N}_{2}$ square planes for complexes $\mathbf{1}$ and $\mathbf{2}$, respectively. However,

\begin{tabular}{|c|c|c|}
\hline \multicolumn{3}{|c|}{$\begin{array}{l}\text { TABLE-1 } \\
\text { CRYSTALLOGRAPHIC DATA FOR COMPLEX } 1 \text { AND COMPLEX } 2\end{array}$} \\
\hline Complex & {$[\mathrm{Cu}(\mathrm{HL})$ (imidazole) $] \cdot \mathrm{ClO}_{4}(\mathbf{1})$} & $2[\mathrm{Cu}(\mathrm{HL})($ pyrazol $)] \cdot \mathrm{ClO}_{4}(2)$ \\
\hline Formula & $\mathrm{C}_{18} \mathrm{H}_{17} \mathrm{~N}_{4} \mathrm{O}_{7} \mathrm{CuCl}$ & $2 \mathrm{C}_{18} \mathrm{H}_{17} \mathrm{~N}_{4} \mathrm{O}_{7} \mathrm{CuCl}$ \\
\hline Formula weight & 500.35 & 1000.71 \\
\hline Crystal system & Triclinic & Triclinic \\
\hline Space group & $\overline{\mathrm{PI}}$ & $\overline{\mathbf{P}}$ \\
\hline Colour & Green & Green \\
\hline a $(\AA)$ & $9.0657(9)$ & $8.472(3)$ \\
\hline b $(\AA)$ & $10.6278(10)$ & $11.041(3)$ \\
\hline $\mathrm{c}(\AA)$ & $11.1888(11)$ & $12.265(3)$ \\
\hline$\alpha\left(^{\circ}\right)$ & $113.497(2)$ & $68.404(4)$ \\
\hline$\beta\left(^{\circ}\right)$ & $92.970(2)$ & $71.303(4)$ \\
\hline$\gamma\left({ }^{\circ}\right)$ & $93.550(2)$ & $68.872(4)$ \\
\hline $\mathrm{V} /\left(\AA^{3}\right)$ & $983.28(17)$ & $971.4(5)$ \\
\hline $\mathrm{D}_{\text {calc }}\left(\mathrm{g} \mathrm{cm}^{-3}\right)$ & 1.690 & 1.765 \\
\hline$\mu\left(\mathrm{mm}^{-1}\right)$ & 1.298 & 1.321 \\
\hline $\mathrm{F}(000)$ & 510 & 526 \\
\hline Range of h, k, 1 & $-9<=\mathrm{h}<=11,-11<=\mathrm{k}<=13,-13<=1<=12$ & $-9<=\mathrm{h}<=10,-10<=\mathrm{k}<=13,-11<=1<=15$ \\
\hline GOF & 1.035 & 1.097 \\
\hline Data/restraints/parameters & $3839 / 0 / 269$ & $3780 / 0 / 281$ \\
\hline $\mathrm{R}_{1}, \mathrm{wR}_{2}[\mathrm{I}>2 \sigma(\mathrm{I})]^{\mathrm{a} . \mathrm{b}}$ & $\mathrm{R}_{1}=0.0576, \mathrm{wR}_{2}=0.1370$ & $\mathrm{R}_{1}=0.0596 \mathrm{wR}_{2}=0.1617$ \\
\hline $\mathrm{R}$ indices (all data) & $\mathrm{R}_{1}=0.0896, \mathrm{wR}_{2}=0.1544$ & $\mathrm{R}_{1}=0.0667, \mathrm{wR}_{2}=0.1682$ \\
\hline Largest diff. peak and hole $\left(\mathrm{e} \AA^{-3}\right)$ & 0.740 and -0.739 & 1.518 and -1.127 \\
\hline \multicolumn{3}{|c|}{${ }^{\mathrm{a}} \mathrm{R}=\Sigma\left\|\mathrm{F}_{\mathrm{o}}|-| \mathrm{F}_{\mathrm{c}}\right\| / \Sigma\left|\mathrm{F}_{\mathrm{o}}\right| ;{ }^{b} \mathrm{w} \mathrm{R}_{2}=\left[\Sigma \mathrm{w}\left(\mathrm{F}_{\mathrm{o}}{ }^{2}-\mathrm{F}_{\mathrm{c}}{ }^{2}\right)^{2} / \Sigma \mathrm{w}\left(\mathrm{F}_{\mathrm{o}}{ }^{2}\right)^{2}\right]^{1 / 2}$} \\
\hline
\end{tabular}




\begin{tabular}{|c|c|c|c|}
\hline \multicolumn{4}{|c|}{ INTRAMOLECULAR HYDROG } \\
\hline \multicolumn{3}{|c|}{$\mathrm{D}-\mathrm{H} \cdots \mathrm{A}$} & $\mathrm{d}(\mathrm{D}-\mathrm{H})$ \\
\hline \multicolumn{3}{|c|}{ N1-H1A $\cdots \mathrm{O} 7$} & 0.88 \\
\hline \multicolumn{3}{|c|}{ 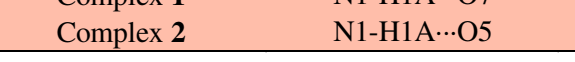 } & 0.88 \\
\hline \multicolumn{4}{|c|}{$\begin{array}{c}\text { TABLE-3 } \\
\text { SELECTED BOND LENGTHS }(\AA) \\
\text { AND ANGLES }\left({ }^{\circ}\right) \text { FOR COMPLEX } 2\end{array}$} \\
\hline \multicolumn{4}{|c|}{ Bond lengths } \\
\hline $\mathrm{Cu} 1-\mathrm{O} 1$ & $1.982(3)$ & Cu1-N2 & 1.923(3) \\
\hline $\mathrm{Cu} 1-\mathrm{O} 2$ & $1.910(3)$ & $\mathrm{Cu} 1-\mathrm{N} 3$ & $1.939(3)$ \\
\hline \multicolumn{4}{|c|}{ Bond angles } \\
\hline O2-Cu1-O1 & $172.61(11)$ & $\mathrm{O} 2-\mathrm{Cu} 1-\mathrm{N} 2$ & $92.23(13)$ \\
\hline N2-Cu1-O1 & $81.11(13)$ & $\mathrm{O} 2-\mathrm{Cu} 1-\mathrm{N} 3$ & $91.63(13)$ \\
\hline N3-Cu1-O1 & $95.53(13)$ & $\mathrm{N} 2-\mathrm{Cu} 1-\mathrm{N} 3$ & $168.28(14)$ \\
\hline
\end{tabular}

none of the two complex molecules as a whole is planar. This is because the twisting of the phenyl ring plane (C1-C6 ) of the benzoyl fragment in $\mathrm{H}_{2} L$ and that of the heterocycle plane (imidazole and pyrazol) with respect to the plane containing rest of the molecule ${ }^{12}$. In complex $\mathbf{1}$, both aromatic rings in each ligand surrounding the copper atoms form a dihedral angle that is $7.34(16)^{\circ}$. Compare to that, the larger dihedral angle found in complex 2 of $30.91(17)^{\circ}$ indicates that the twist of $\mathrm{H}_{2} L$ in $\mathbf{1}$ is significantly smaller than in 2 . The nature of different $\mathrm{N}$-donor heterocycles may result in the different twist of $\mathrm{H}_{2} L$, although it is difficult to rationalize these outcomes at present $^{23}$. The dihedral angles between the phenyl ring plane and the pyrazol plane are $17.34(17)^{\circ}$ and $8.04(18)^{\circ}$ for complexes $\mathbf{1}$ and $\mathbf{2}$, respectively. In the crystal structure of complexes $\mathbf{1}$ and $\mathbf{2}$, the uncoordinated perchlorate anion is involved in forming intramolecular hydrogen bonds (Figs. 1 and 2 and Table-4).

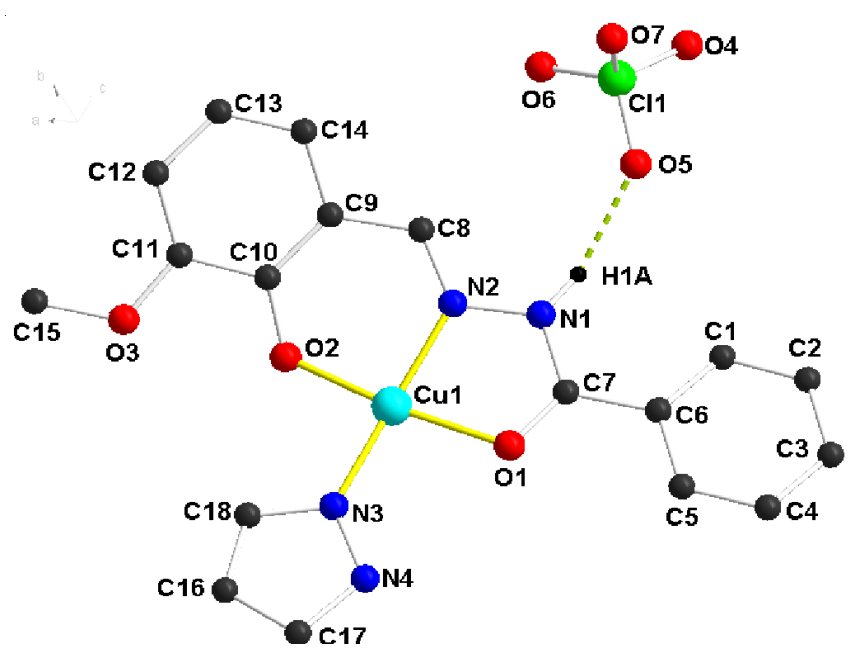

Fig. 2. A view of the complex $\mathbf{2}$, showing the atomic numbering scheme

Square-planar $\mathrm{Cu}$ (II) complexes are known to form dimeric species containing equatorial-apical bridges due to the involvement of the metal ion in weak interactions with another atom of a neighboring molecule at the apical position ${ }^{24,25}$. Complex 2 forms a centrosymmetric dimeric species due to weak apical coordination of the phenolate-O in a reciprocal fashion (Fig. 3). The Cu1-O2A distance is 2.4343(33) $\AA$. In the $\mathrm{Cu}_{2} \mathrm{O}_{2}$ core,

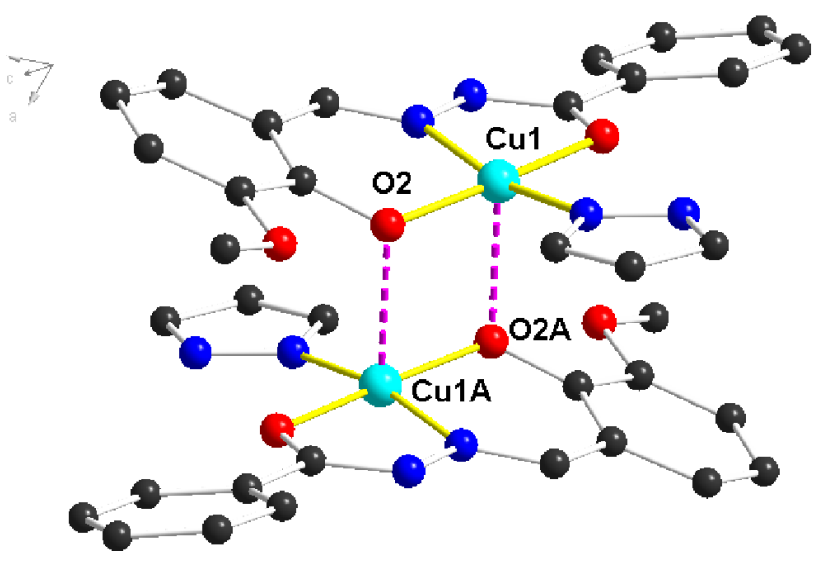

Fig. 3. Dimeric structure of the complex 2

the $\mathrm{Cu} 1-\mathrm{O} 2-\mathrm{Cu} 1 \mathrm{~A}$ bridge angle and the $\mathrm{Cu} 1 \cdots \mathrm{Cu} 1 \mathrm{~A}$ distance are $94.765(15)^{\circ}$ and $3.2167(13) \AA$.

\section{Conclusion}

To summarize, two novel mononuclear $\mathrm{Cu}$ (II) complexes have been prepared by using the Schiff base ligand $\left(\mathrm{H}_{2} \mathrm{~L}\right)$. The both $\mathrm{Cu}$ (II) ions adopt a $\mathrm{CuN}_{2} \mathrm{O}_{2}$ distorted square-planar coordination environment. However, the different N-donor heterocycles of two complex molecules may result in the different twist of $\mathrm{H}_{2} \mathrm{~L}$. In addition, complex 2 forms a centrosymmetric dimeric species due to weak apical coordination of the phenolate-O in a reciprocal fashion.

\section{ACKNOWLEDGEMENTS}

The authors thank the project supported by the Science and Technology Department of Changchun City, China (Grant No. 2012098, Plan Item No. 12SF26) and Changchun University of Science and Technology for their financial support.

\section{REFERENCES}

1. P.H. Lin, T.J. Burchell, L. Ungur, L.F. Chibotaru, W. Wernsdorfer and M. Murugesu, Angew. Chem. Int. Ed., 48, 9489 (2009).

2. E.-C. Yang, W. Wernsdorfer, S. Hill, R.S. Edwards, M. Nakano, S. Maccagnano, L.N. Zakharov, A.L. Rheingold, G. Christou and D.N. Hendrickson, Polyhedron, 22, 1727 (2003).

3. J.R. Dilworth, Coord. Chem. Rev., 21, 29 (1976).

4. J.R. Merchant and D.S. Chothia, J. Med. Chem., 13, 335 (1970).

5. L. Pickart, W.H. Goodwin, W. Burgua, T.B. Murphy and D.K. Johnson, Biochem. Pharmacol., 32, 3868 (1983).

6. H.H. Monfared, Z. Kalantari, M.A. Kamyabi and C. Janiak, Z. Anorg. Allg. Chem., 633, 1945 (2007).

7. H.H. Monfared, J. Sanchiz, Z. Kalantari and C. Janiak, Inorg. Chim. Acta, 362, 3791 (2009).

8. D. Matoga, J. Szklarzewicz, K. Stadnicka and M.S. Shongwe, Inorg. Chem., 46, 9042 (2007).

9. M. Albrecht, Y.F. Liu, S.C.S. Zhu, C.A. Schalley and R. Frohlich, Chem. Commun., 1195 (2009).

10. M.K. Ehlert, A. Storr and R.C. Thompson, Can. J. Chem., 70, 1121 (1992).

11. S. Trofmenko, Prog. Inorg. Chem., 34, 115 (1986).

12. S. Das and S. Pal, J. Mol. Struct., 741, 183 (2005). 
13. M.F. Iskander, T.E. Khalil, R. Werner, W. Haase, I. Svoboda and H. Fuess, Polyhedron, 19, 1181 (2000)

14. O. Pouralimardan, A.-C. Chamayou, C. Janiak and H. HosseiniMonfared, Inorg. Chim. Acta, 360, 1599 (2007).

15. L.Z. Sacconi, Anorg. Allg. Chem., 275, 249 (1954).

16. G.M. Sheldrick, SHELXS-97, Program for Crystal Structure Solution, University of Göttingen, Germany (1997).

17. G.M. Sheldrick, SHELXL-97, Program for Crystal Structure Refinement, University of Göttingen, Germany (1997).

18. M.F. Iskander, T.E. Khalil, W. Haase, R. Werner, I. Svoboda and H. Fuess, Polyhedron, 20, 2787 (2001).
19. N.R. Sangeetha and S. Pal, Polyhedron, 19, 1593 (2000).

20. S. Das and S. Pal, J. Mol. Struct., 753, 68 (2005).

21. N.R. Sangeetha, S.N. Pal, C.E. Anson, A.K. Powell and S. Pal, Inorg. Chem. Commun., 3, 415 (2000).

22. G.-M. Yu, L. Zhao, Y.-N. Guo, G.-F. Xu, L.-F. Zou, J. Tang and Y.-H. Li, J. Mol. Struct., 982, 139 (2010).

23. L.F. Zou, L. Zhao, Y.-N. Guo, J. Tang, Q.-L. Wang and Y.-H. Li, Inorg. Chim. Acta, 382, 65 (2012).

24. N.R. Sangeetha and S. Pal, Polyhedron, 19, 1593 (2000).

25. H.Y. Liu, Z.S. Lu and D.Z. Niu, J. Coord. Chem., 61, 4040 (2008). 